\title{
Mobile Game Design Based on Classic Cartoon
}

\author{
Yingfang Zhang*, Siyang Lu and Yinglu Tang \\ Sino-Korean School of Multimedia Design, Shanghai University of Engineering Science, Shanghai, China \\ ${ }^{*}$ Corresponding author
}

\begin{abstract}
Mobile electronic games with the hand-phone as the carrier have gradually become a necessary product for people's leisure and entertainment in twenty-first Century. They have become a new way to inherit the excellent traditional culture of various countries, so the design and development of the game based on the classic animation will become one of the development trends. In this paper, in order to restore the classic scenes and plot as the main content, combined with China traditional culture and new media interactive methods, describes the process of cohesion and creation of game design and traditional culture, a drama shooting mobile game is designed which combines $2 \mathrm{D}$ and $3 \mathrm{D}$ and its creation foundation is a traditional animation.
\end{abstract}

Keywords-component; mobile game; game design; cartoon; calabash brothers

\section{INTRODUCTION}

Mobile electronic games with the hand-phone as the carrier have gradually become a necessary product for people's leisure and entertainment in twenty-first Century. At present, the research and development of mobile games are more focused on creating new themes and genres [1]. It is a few successful cases which combines mobile game with traditional cartoon because the use of the traditional culture is relatively weak. Development of mobile games with Chinese characteristics will become one of the development trends [2]. As the carrier of Chinese excellent traditional culture, classic cartoon "Calabash Brothers", the mobile game can be regarded as a new way of communication. This paper will explore the combination of animation and game art element, Chinese traditional animation into the character design of mobile games, create player favorite game, and show the charm of the Chinese nation unique oriental charm and culture in the artistic values, aesthetic values, customs and other aspects etc. [3][4].

The game in this paper is implemented in Unity engine. It is developed by Unity Technologies Company which is a multi-platform game development tools, and a comprehensive professional game engine. Three-dimensional video games, architectural visualization, real-time three-dimensional animation and other types of interactive content can be easily created with Unity. It uses interactive graphical development environment software editor as the main form, runs on windows and Mac OS X operating system, releases to games for windows, MAC, Wii, iPhone, Windows Phone 8 and Android platform, supports embedded in web pages. Currently Unity is widely used in games, construction estate, virtual display, education and training, industrial simulation, system simulation and others.
Unity is divided into two parts, the game engine and the editor. The game engine covers physical simulation, graphical interface, audio channel, and network capabilities, which are common in game research and development. Its script is based on Mono, C\#, Boo, and JavaScript programming. The Unity editor is a integrated development environment of the game scene setting, the game preview window, and the layered object project panel. It is also equipped with several language script editors and a unique prefabricated assembly system.[5]

\section{DESIGN OF THE GAME “CALABASH BROTHERS”}

\section{A. Game Plot}

The "Calabash Brothers" Game tells the story of seven boys together to eliminate the fairy tale. The scorpion and snake gourd were shut in Calabash Mountain. A pangolin accidentally made a hole through the mountain, then two large goblins escaped, and was harmful of the world of people. An old man passing the mountain encountered pangolin and rescued it. The pangolin told the old man about the disaster, and hoped to get help from him. There is only one way, planting and growing seven color calabashes, to kill the two big geniuses and restore the world calm. Grandpa grew red, orange, yellow, green, gray, blue, purple seven big calabashes. The snake genius had a glimpse from a mirror. They wanted to destroy the gourd before fruit mature. When the strategy failed they seized the old man and the pangolin. Seven calabashes matured, landed and became seven boys, wearing seven different colors of clothes; their skills are not the same. In the game players select the different color boys, complete five levels, the final assembly of seven colors of lotus seed, then put them into the alchemy furnace, turned into a colorful lotus which can kill two big geniuses[6][7].

The game set up five levels after extracting the main story, which is destroying the toad sperm; killing bees; destroying beetle monster; destroying the bat; and overcoming the ultimate boss snake and scorpion.

\section{B. Game Play Design}

The game play is mainly through click by one or more of the fingers, drag and other operations, shown as table 1 . Players choose different characters; look for monsters in a three hundred and sixty degrees full range of scenes in the mobile device, shoot monsters with the aim point.

There are two types of monsters in each level, the small monster closes to the player by moving, and the impact of the player's screen damage, the player must destroy the monster when they are near. The big monster randomly appears in any 
place in the scene after a certain amount of small ones eliminated. It will have a unique skill, random movement, direct damage to the player. Players cannot be avoided, as soon as possible to use the ability to destroy the monster. Aiming point appears on big monsters body after their blood is just to $1 / 3$. There will be three times. The player must aim at the aiming point and attack, otherwise the attack is invalid. There are a total of five levels, and the player must continue succeed. If you fail, you will need to play from the beginning. Players can also withdraw, back to characters selecting interface and reselect one boy, continue the game after he win in some level.

TABLE I. THE GAME OPERATIONS LIST

\begin{tabular}{|l|l|l|l|}
\hline $\begin{array}{l}\text { Operatio } \\
\text { n gesture }\end{array}$ & \multicolumn{1}{|c|}{$\begin{array}{c}\text { Operation } \\
\text { role }\end{array}$} & \multicolumn{1}{|c|}{$\begin{array}{c}\text { Operating } \\
\text { position }\end{array}$} & \multicolumn{1}{|c|}{ skill effect } \\
\hline Click & $\begin{array}{l}\text { Red boy } \\
\text { Purple boy } \\
\text { Below the middle } \\
\text { of the screen } \\
\text { Calabash shape } \\
\text { aiming point }\end{array}$ & $\begin{array}{l}\text { Brown stone } \\
\text { Purple Light iris }\end{array}$ \\
\hline $\begin{array}{l}\text { Hands } \\
\text { Click }\end{array}$ & Orange boy & $\begin{array}{l}\text { eye shape aiming } \\
\text { point }\end{array}$ & Orange laser \\
\hline $\begin{array}{l}\text { a finger } \\
\text { sliding } \\
\text { screen }\end{array}$ & Yellow boy & $\begin{array}{l}\text { Below the middle } \\
\text { of the screen }\end{array}$ & Flying knife \\
\hline $\begin{array}{l}\text { Hands } \\
\text { long press } \\
\text { the screen }\end{array}$ & $\begin{array}{l}\text { Green boy } \\
\text { Blue boy } \\
\text { Gray boy }\end{array}$ & $\begin{array}{l}\text { Below the middle } \\
\text { of the screen }\end{array}$ & $\begin{array}{l}\text { Orange red ball } \\
\text { Blue water } \\
\text { Light blue light } \\
\text { beam }\end{array}$ \\
\hline
\end{tabular}

\section{Game Art Design}

The modeling and design of a game is first exposed to players, so its quality directly affects the level of play. If the character design is black and white, the game will be very easy to be neglected. So in the process of making the game various art designs is very diverse, with pictures of the opening animation, ink style game starting screen, paper-cut style characters detailed interface. Each style is interspersed with each other, mutual influence. Because now 3D game is the mainstream trend of the market game, the monsters in this work are designed as characters $3 \mathrm{D}$, as far as possible to restore the original image of the role.

In the creation of "Calabash Brothers", the art of Chinese style is mainly applied to the design of scene elements and characters.

Calabash boys have characteristics as justice, good, honest, simple and so on, which is in line with the spirit of contemporary children's portrayal. But enemies such as the snake, scorpion king are sinister and cunning. In the cartoon movie, calabash boys have a square face, short thick eyebrows, bright eyes, stocky body, head and neck wearing a crown gourd leaf collar, wearing a vest shorts, waist skirt gourd leaf etc.. Square face with Chinese cultural tradition are consistent with upright and outspoken ideas, they are the embodiment of justice, so the game features in the design highlights its justice brave, crown, gourd leaf collar and short skirts, is a prominent feature of popular calabash boys image [8][9]. The seven calabash boy characters are shown as Figure I.
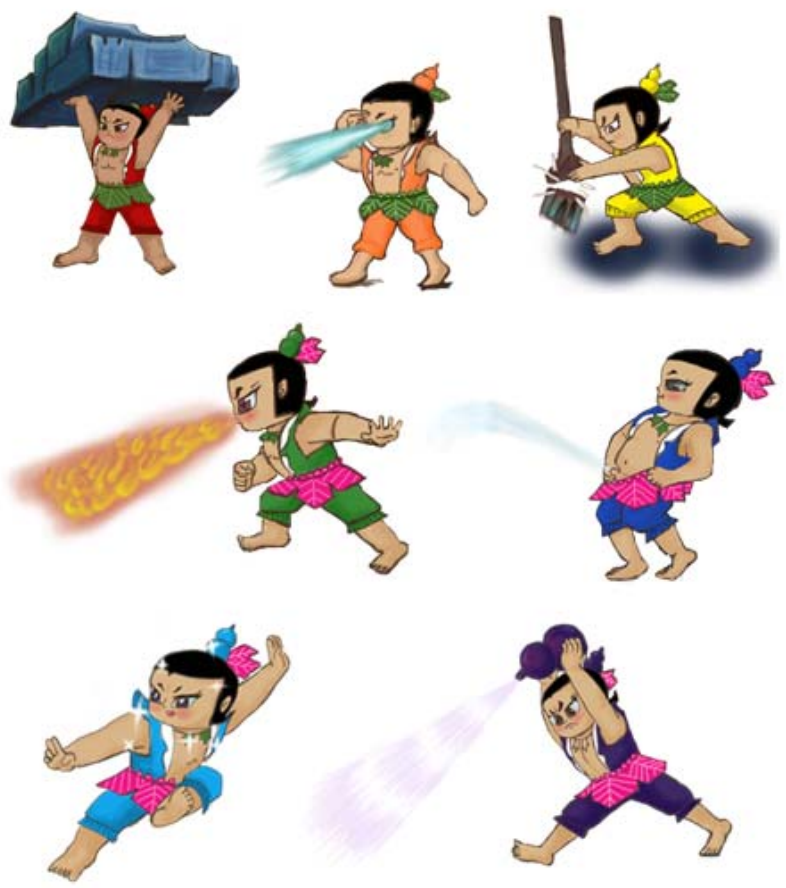

FIGURE I. THE SEVEN CALABASH BOYS CHARACTERS

The user interface design of the game basically followed the original style, combination of ink elements and the paper cutting style. As most of boys fight with monsters scenes in the cartoon film is in a cave, the works main tone of the UI is blue, the overall dark, the design of the whole game style diversity and unity. In order to better show the different characters of each role, different roles match different scenes.

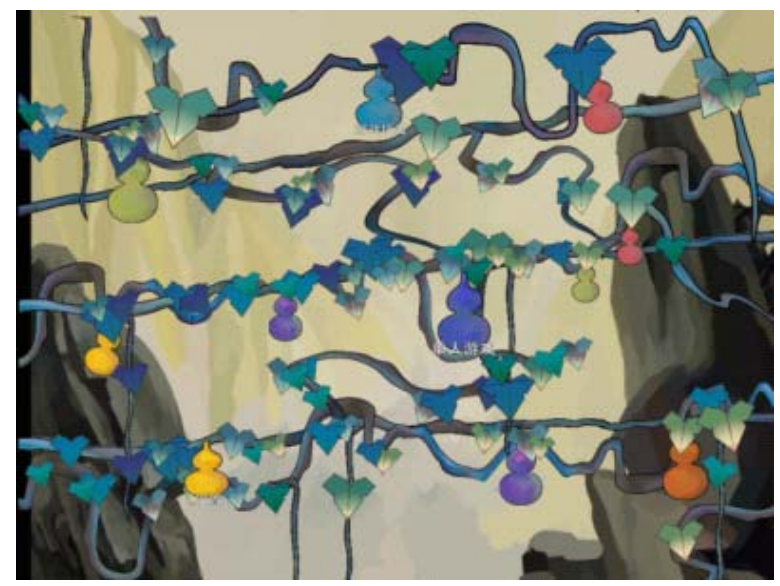

FIGURE II. THE GAME'S BEGINNING INTERFACE

The beginning interface uses gourd vine, the most direct expression of the game's plot (shown as Figure II). Selecting level interface uses monsters that are the most familiar make the game more a sense of substitution after plot selection. Selecting roles interface uses paper-cutting style, so that players can quickly understand the characteristics of each role attributes. The dialogue introduced the story is joined to the starting animation as the first point of view, so that the game is 
full of story and fun. One of the game levels interface is shown as Figure III.

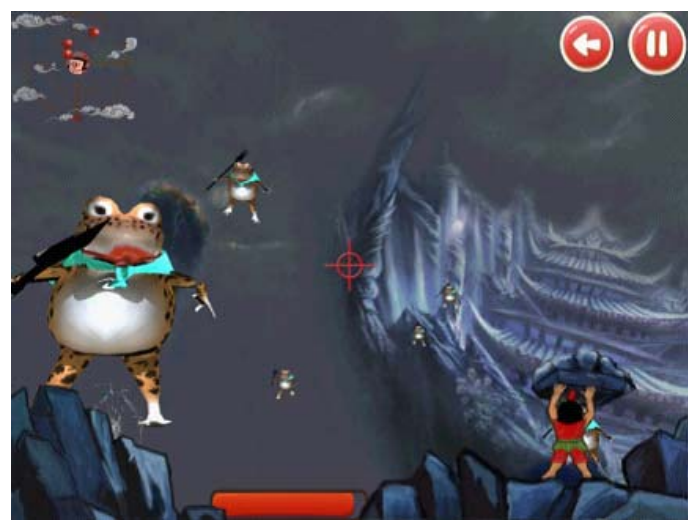

FIGURE III. THE GAME’S LEVEL INTERFACE

\section{GAME IMPLEMENTATION}

Unity3D engine is playing a more and more important role for the game industry. The Unity3D utilization rate is $75 \%$ that ranks first globally at Chinese hand-games market according to data statistics in August 2014. Development cycle of game is shorter, less difficulty by using Unity3D. Unity engine is developed by Unity Technologies Company which is a multiplatform game development tools, and a comprehensive professional game engine. Three-dimensional video games, architectural visualization, real-time three-dimensional animation and other types of interactive content can be easily created with Unity. It uses interactive graphical development environment software editor as the main form, runs on windows and Mac OS X operating system, releases to games for windows, MAC, Wii, iPhone, Windows Phone 8 and Android platform, supports embedded in web pages. Currently Unity is widely used in games, construction estate, virtual display, education and training, industrial simulation, system simulation and others [8]. The game in this paper is developed in Unity3D.

\section{A. Game Flow}

An animation, which is made of eight pictures for the game plot, introduces the game. The beginning interface mainly has several parts of entering game, play introduction, the game settings, help etc. It jumps to the level interface when the button "enter the game" is clicked, and jump to choosing the interface with seven characters when any level button is clicked. After selecting a character the game's main interface is shown, that is made of background of the game, calabash boys on behalf of the player, monsters and their blood bars, pause key, return key and other elements. After passing five levels the animation and winning tips are displayed.

\section{B. Game Development Process}

The development process of the game mainly has the following four stages:
- Prototype stage: set a very simple scene, achieve the main functions of the game, try a variety of interactive methods, and test the results.

- Alpha stage: this stage will finalize the game specific process planning, plus the interface data and the level set, the production of the game each level user interface effect.

- Beta stage: the production of roles and scenes using the interface style, strengthen the setting details, optimize the difficulty degree and game funny.

- Product stage: transplanted to the mobile device for testing, debugging, repair bugs, flash back and other issues, this is the final stage of the game.

\section{CONCLUSION}

The mobile game is one of the new interactive activities in modern times as the largest Chinese social and entertainment. In the design and development process, the primary task is the continuous innovation in the international game, how China Mobile game appears in people's field of vision. This article introduces the application of the classic animated film in mobile games; the works "Calabash Brothers" have its own advantages and conditions of creation. Select the distinctive national characteristics of the story, give the game with a strong cultural heritage support. Therefore, in the design process of the game, the emphasis lies in the combination of traditional culture and new media interactive means, emphasizing how the game design and the traditional culture of convergence and its creative process.

\section{REFERENCES}

[1] Chen Meizhen, Wang Daiming was, When the literary masterpiece: regeneration or destruction suffered electronic games -- Taking Three Kingdoms as an example [J]. film literature, 2008 (12): 119-12

[2] Wang Chengyu. China research topics in network game art masterpiece of art [J]., 2012 (3): 76-76

[3] Feng Ting, Dong Mangdi. From the perspective of the classic masterpiece spread function adapted research network game -- A Fantasy Westward Journey, for example [J]. xijiangyue, 2013

[4] Ma Jiang Wei. Digital game art and China elements of the traditional thinking of [J]. literature and art, 2010 (1)

[5] Will Goldstone, Unity 5.x Game Development Essentials[M], Packt Publishing,2015.

[6] Calabash Brothers[EB], http://baike.so.com/doc/2317583-2451430.html

[7] . Yuliang Yang, Zhongli Yao, Du Mo. Calabash Brothers[M], Spring Art Publishing House ,2012

[8] .Zhongli Yao, Yuliang Yang, Du Mo. Calabash Brothers, Shanghai art film studio,1986

[9] Guo Ruijing, game action control and design based on Unity3D [J], Journal of Lanzhou College of Arts and Sciences: Natural Science Edition, 2015 